\title{
How does area-level deprivation depress an individual's self-rated health and life satisfaction? Evidence from a nationwide population-based survey in Japan
}

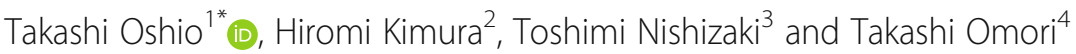

\begin{abstract}
Background: Area-level deprivation is well known to have an adverse impact on mortality, morbidity, or other specific health outcomes. This study examined how area-level deprivation may affect self-rated health (SRH) and life satisfaction (LS), an issue that is largely understudied.

Methods: We used individual-level data obtained from a nationwide population-based internet survey conducted between 2019 and 2020, as well as municipality-level data obtained from a Japanese government database $(N=12$, 461 living in 366 municipalities). We developed multilevel regression models to explain an individual's SRH and LS scores using four alternative measures of municipality-level deprivation, controlling for individual-level deprivation and covariates. We also examined how health behavior and interactions with others mediated the impact of arealevel deprivation on SRH and LS.

Results: Participants in highly deprived municipalities tended to report poorer SRH and lower LS. For example, when living in municipalities falling in the highest tertile of municipality-level deprivation as measured by the $z-$ scoring method, SRH and LS scores worsened by a standard deviation of $0.05(p<0.05)$ when compared with those living in municipalities falling in the lowest tertile of deprivation. In addition, health behavior mediated between 17.6 and $33.1 \%$ of the impact of municipality-level deprivation on SRH and LS, depending on model specifications.

Conclusion: Results showed that area-level deprivation modestly decreased an individual's general health conditions and subjective well-being, underscoring the need for public health policies to improve area-level socioeconomic conditions.
\end{abstract}

Keywords: Area-level deprivation, Multilevel mediation analysis, Self-rated health, Subjective well-being

\section{Background}

It is well known that area-level socioeconomic conditions have a contextual association with an individual's health outcomes [1-3]. Many studies have indicated that area-level deprivation, which reflects various aspects of

\footnotetext{
* Correspondence: oshio@ier.hit-u.ac.jp

'Institute of Economic Research, Hitotsubashi University, 2-1 Naka, Kunitachi, Tokyo 186-8603, Japan

Full list of author information is available at the end of the article
}

an area's socioeconomic positions, can affect the health outcomes of its residents, including mortality [4-7], morbidity [8-11], mental health [12, 13], poor birth outcomes $[9,14,15]$, and health risk behavior $[16,17]$. The impact of area-level deprivation on health matters for not only public health policies but also macroeconomic and social policies committed to income redistribution, labor market regulations, and other issues related to social welfare. 
To capture small-area socioeconomic deprivation, a variety of deprivation measures have been developed $[18,19]$. These measures generally cover multiple dimensions of deprivation, such as income, employment, education, social class, and housing conditions. To construct a single index of deprivation, the most straightforward way is to sum standardized scores ( $z$-scores) of each dimension with an equal weight (e.g., Townsend and Carstairs indices $[20,21])$ or different weights (e.g., Jarman index [22]). To avoid normative judgment that is inevitably involved in any weighting, the principal component and factor analysis approaches, which assign a set of weights that statistically best explain the variation in the data, have also been often used [23-25]. Because all of these approaches are known to have both advantages and disadvantages and have no clear theoretical background [18], it may be useful to compare their results and assess their robustness.

Regarding the association between area-level deprivation and health, two issues remain to be addressed. First, the impact on self-rated health (SRH), which represents overall health conditions [26, 27], or subjective well-being (SWB), which is often expressed by life satisfaction (LS), has been relatively understudied, compared to the impact of area-level deprivation on mortality, morbidity, or other specific health outcomes [4-16]. Meanwhile, many studies have shown that individual-level SWB measures were related to area-level objective well-being. Residents in areas with more favorable socio-economic characteristics were found to be happier and more satisfied with life [28-31]. Studies have also examined the association between arealevel income inequality or poverty and an individual's SRH or SWB [32-34]. Hence, it is of interest to know whether the same is true for area-level deprivation, which captures other domains of area-level socioeconomic positions rather than just income.

Second, the factors that may mediate the impact of area-level deprivation on SRH and LS need to be further addressed. Specific factors such as the availability of alcohol, the physical environment, and maternal health have been found to mediate the impact of neighborhood deprivation on alcohol consumption, some health biomarkers, and preterm birth, respectively $[15,35,36]$. In the case of the impact on SRH and SWB, health behavior and/or interactions with neighbors/friends, both of which are well known to affect them [37-40], could be potential mediators. In particular, the mediating effect of health behavior, if any, would have an important policy implication because public policies for healthy lifestyle promotion could then be expected to mitigate the adverse impact of area-level deprivation.

Keeping these issues in mind, this study conducted a multilevel analysis to examine how an individual's SRH and LS were associated with municipality-level deprivation in Japan, where regional disparities in health resumed a widening trend in the mid-1990s [41, 42]. An increasing number of studies have examined the importance of arealevel socioeconomic conditions as a contextual determinant of health among Japanese people. Specifically, some studies examined how municipality-level socioeconomic positions are associated with mortality or life expectancy [4], while other studies investigated how neighborhood deprivation is related to all-cause mortality [6], as well as the risk of incidence, mortality, and survival from cancers [11]. However, more investigation into its impact on SRH or LS as well as its potential mediators is needed for a more comprehensive understanding of the relevance of area-level deprivation for an individual's well-being.

\section{Methods}

Study sample

This study used data obtained from a population-based, nationwide internet survey conducted as a research project of the Cabinet Office (CAO) of the Japanese government in October 2019 and again in February 2020. The survey was conducted in accordance with Japan's Statistics Law, which governs the statistical, legal, ethical, and other rules for surveys conducted by the government. Informed consent was obtained from all participants. We obtained the data of the survey with the permission of the $\mathrm{CAO}$; therefore, ethics approval was not required for the current study.

We distributed the questionnaires to the registrants of an internet survey company. We planned to collect data from approximately 15,000 participants: around 10,000 from the survey in 2019 and the remaining 5000 from the survey in 2020. We divided the targeted sample into two groups. First, we distributed 11,280 registrants equally between each of the 47 prefectures, between men and women, and among five age groups (aged 15$24,25-34,35-44,45-59$, and 60+). Thus, each prefecture-gender-age group consisted of 24 individuals. Next, we allocated the remaining 4245 registrants to each gender-age group in each prefecture in proportion to each prefecture's actual population size. When we closed the survey, we had obtained data from 15,574 participants. It should be noted that this construction of the dataset made the residents living in the metropolitan areas underweighted compared to the actual population.

We used municipality, which is the basic unit of local administration in Japan, for a unit of area. From a total of 1741, the current study collected data from $1273 \mathrm{mu}$ nicipalities with the number of participants ranging from 1 to 257 (mean [M] 12.2 and standard deviation [SD] 25.4). Excluding data from municipalities with less than ten participants and also participant data missing key variables, we used data from 12,461 participants (6157 men and 6304 women) living in 366 municipalities, 
where the number of participants from each municipality ranged between 1 and 257 (M 34.0 and SD 38.5).

\section{Measures \\ Individual-level variables}

Regarding SRH, the survey asked the participants to answer the question: "How do you feel about your health condition?" by choosing good, somewhat good, average, somewhat poor, or poor. We constructed a continuous variable of SRH by allocating 1 to poor and 5 to good (the higher, the better). The survey also asked the participants to answer the question: "In general, how satisfied are you with your life?" by responding on an 11-point scale $(0=$ not satisfied at all to $10=$ highly satisfied). We constructed a continuous variable of LS (the higher, the more satisfied).

We also considered health behavior and interactions with others. Regarding health behavior, the survey asked the participants whether they were usually doing the following for their health: 1) eating a balanced diet, 2) exercising, 3) getting enough sleep, 4) refraining from smoking, 5) refraining from excess alcohol consumption, 6) avoiding the accumulation of stress, 7) going for regular checkups, 8) doing nothing in particular, and 9) other. We constructed a continuous variable of health behavior by adding up the number of chosen items from 1 to 7 . As for interactions with others, the survey asked participants how often they interacted with friends or others. We constructed a continuous variable of interactions with others by allocating $7,7 / 2,1,2.5 / 4,1 / 4,1 / 16$, $1 / 48$, and 0 to almost every day, three or four times a week, once a week, twice or thrice a month, sometimes a year, once a year, and no one to interact with, respectively.

We considered individual-level deprivation in terms of income, education (graduated from junior high school only), and job status (unemployed). Regarding income, we adjusted the reported amount by household size by dividing household income by the square root of the number of household members. We subsequently defined income poverty as an adjusted household that fell below the official poverty line, which is 1.22 million JPY at 2015 price, as defined by the Japanese Ministry of Health, Labor and Welfare (MHLW) [43]. As individual-level covariates, we considered gender, age group (29 or below, 30s, 40s, 50s, and 60 or above), marital status (having a spouse or not), and survey years (2019 or 2020).

\section{Municipality-level variables}

At the municipality level, we selected seven indicators: 1 ) the percentage of unemployed persons, 2) the percentage of persons who had an educational attainment of college or above, 3) taxable income per capita, 4) the percentage of owned houses, 5) the percentage of households with floor space per capita that was below the minimum level (defined by the Ministry of Land, Infrastructure, Transport and Tourism [44]); 6) the percentage of single-parent households, and 7) the percentage of aged single households. The choice of indicators largely followed those of preceding studies [4, 20-22]. Specifically, the indicators 1) to 4) correspond to general socioeconomic conditions, 5) represents the extent of household overcrowding, and 6) and 7) represent prevalence of vulnerable groups. We downloaded this data from the website database for municipality-level socioeconomic indicators, which are based on government surveys conducted around the year 2015. This official database is provided by the Ministry of Internal Affairs and Communications [45].

\section{Analytic strategy}

We computed the municipality-level deprivation indices in two ways. First, we conducted the $z$-scoring method by summing the $z$-scores of each indicator. In this calculation, we revered the signs of taxable income per capita and the percentage of owned houses, both of which were expected to make a negative contribution to municipalitylevel deprivation. Second, we conducted a principal component analysis (PCA) and selected components for which the eigenvalue of the correlation matrix was more than one as significant dimensions. Two or three principal components were expected to be obtained as significant dimensions. We calculated scores based on each of these components as well as their sum as deprivation indices. We categorized each deprivation index into tertiles: low, moderate, and high.

For the statistical analysis, we estimated multilevel linear regression models to explain SRH/LS scores by binary variables of moderate and high levels of each deprivation index (using low deprivation as a reference) along with individual-level deprivation and covariates. We compared the results across different methods of constructing the deprivation index.

We then conducted a multilevel mediation analysis to examine whether and to what extent health behavior and interactions with others mediated the association between municipality-level deprivation and SRH/LS. In the case of health behavior for SRH, we estimated a structural equation model consisting of 1) a model to explain health behavior by deprivation, 2) a model to explain interactions with others by deprivation, and 3) a model to explain SRH by deprivation, health behavior, and interactions with others, and then calculated the mediation effects of health behavior and interactions with others based on the estimated parameters. Denoting the scores of health behavior, interactions with others, and SRH as HBEHAV, INTERACT, and SRH, respectively, and the binary variables of moderate and high deprivation as Moderate and High, respectively, we 
estimated the structural equation model for individual $j$ living in municipality $i$ :

$$
\begin{aligned}
& \text { HBEHAV } V_{i j}=\beta_{11} \text { Moderare }_{i}+\beta_{12} \text { High }_{i} \\
& + \text { (individual-level variables) }+u_{1 i} \\
& +\varepsilon_{1 i j} \\
& \text { INTERACT }_{i j}=\beta_{21} \text { Moderate }_{i}+\beta_{22} \text { High }_{i} \\
& + \text { (individual-level variables) }+u_{2 i} \\
& +\varepsilon_{2 i j} \text {, } \\
& S R H_{i j}=\beta_{31} \text { Moderate }_{i}+\beta_{32} \text { High }_{i} \\
& +\gamma_{1} H B E H A V_{i j}+\gamma_{2} \text { INTERACT }_{i j} \\
& + \text { (individual-level variables) }+u_{3 i} \\
& +\varepsilon_{3 i j} \text {, }
\end{aligned}
$$

where $u$ denotes municipality-level fixed effects, and $\varepsilon$ an error.

Based on the estimated regression coefficients, we calculated the mediating effects. For the impact of living in municipalities with high deprivation on SRH, we derived the mediating effects of health behavior and interactions with others as $\beta_{12} \gamma_{1}$ and $\beta_{22} \gamma_{2}$, respectively, using participants living in the municipalities. If the mediating effect was found significant, we further computed its proportion out of the entire impact of living in highly deprived municipalities on SRH as $\beta_{12} \gamma_{1} /\left(\beta_{32}+\beta_{12} \gamma_{1}+\beta_{22} \gamma_{2}\right) \times$ $100 \%$ in the case of health behavior. Similarly, we computed the mediating effects of living in moderately deprived municipalities. We also repeated the same estimation procedure for LS. We used the software package Stata (Release 16) for the statistical analysis.
Finally, we repeated a similar analysis by replacing the variable of overall health behavior with a binary variable of each of seven types of health behavior and examined their relative importance for SRH and LS. For all statistical analyses, we used the software package Stata (Release 15).

\section{Results}

Table 1 summarizes the key features of the participants used in this study. No substantial differences were observed between samples collected in 2019 and 2020. In the entire sample, $12.9 \%$ of the participants had an income below the poverty line, $2.7 \%$ had not graduated from high school or above, $3.2 \%$ were unemployed, and $25.8 \%$ had no spouse. As is often the case of Internet surveys, the educational attainment of the respondents was biased upward; the proportion of those who had graduated from college or above was $45.5 \%$, much higher than $26.6 \%$ in the MHLW's Comprehensive Survey of Living Conditions in 2016 [41]. The SRH score had a M of 2.7, a SD of 1.0 , and the LS score had an M of 4.2, and a SD of

\begin{tabular}{|c|c|c|c|c|c|c|}
\hline & \multicolumn{2}{|l|}{ All } & \multicolumn{2}{|c|}{ Surveyed in 2019} & \multicolumn{2}{|c|}{ Surveyed in 2020} \\
\hline \multicolumn{7}{|l|}{ Proportion (\%) } \\
\hline Men & \multicolumn{2}{|l|}{49.4} & \multicolumn{2}{|l|}{49.5} & \multicolumn{2}{|l|}{49.3} \\
\hline Women & \multicolumn{2}{|l|}{50.6} & \multicolumn{2}{|l|}{50.5} & \multicolumn{2}{|l|}{50.7} \\
\hline Income poverty & \multicolumn{2}{|l|}{12.9} & \multicolumn{2}{|l|}{12.7} & \multicolumn{2}{|l|}{13.3} \\
\hline \multicolumn{7}{|l|}{ Educational attainment } \\
\hline Junior high school & \multicolumn{2}{|l|}{2.7} & \multicolumn{2}{|l|}{2.8} & \multicolumn{2}{|l|}{2.6} \\
\hline High school & \multicolumn{2}{|l|}{51.7} & \multicolumn{2}{|l|}{51.6} & \multicolumn{2}{|l|}{51.9} \\
\hline College or above & \multicolumn{2}{|l|}{45.5} & \multicolumn{2}{|l|}{45.6} & \multicolumn{2}{|l|}{45.5} \\
\hline Unemployed & \multicolumn{2}{|l|}{3.2} & \multicolumn{2}{|l|}{3.4} & \multicolumn{2}{|l|}{2.7} \\
\hline \multirow[t]{2}{*}{ Having no spouse } & \multicolumn{2}{|l|}{25.8} & \multicolumn{2}{|l|}{26.1} & \multicolumn{2}{|l|}{25.3} \\
\hline & M & SD & M & $S D$ & M & $S D$ \\
\hline Income ${ }^{a}$ & 3.95 & (6.52) & 3.96 & $(6.75)$ & 3.94 & $(6.06)$ \\
\hline Age & 43.9 & (16.3) & 43.7 & $(16.3)$ & 44.2 & $(16.3)$ \\
\hline Self-rated health $(1-5)^{b}$ & 2.7 & (1.0) & 2.7 & $(1.0)$ & 2.7 & $(1.0)$ \\
\hline Life satisfaction $(0-10)^{c}$ & 4.2 & (2.3) & 4.2 & $(2.4)$ & 4.2 & $(2.3)$ \\
\hline$N$ & \multicolumn{2}{|l|}{12,461} & \multicolumn{2}{|l|}{8246} & \multicolumn{2}{|l|}{4215} \\
\hline
\end{tabular}
2.3. Figure 1 presents the histograms of SRH and LS. While SRH had a central, single peak at 3, LS had two peaks at 5 and 7 and somewhat more left-skewed distribution. These two scores were highly correlated with each other, with a correlation coefficient being $0.38(p<0.001)$.

Table 2 presents pairwise correlation coefficients across municipality-level SRH, LS, and the seven

Table 1 Key features of the study sample

${ }^{a}$ Household size adjusted. Annual, million JPY

b The higher, the poorer

c The higher, the less satisfied 


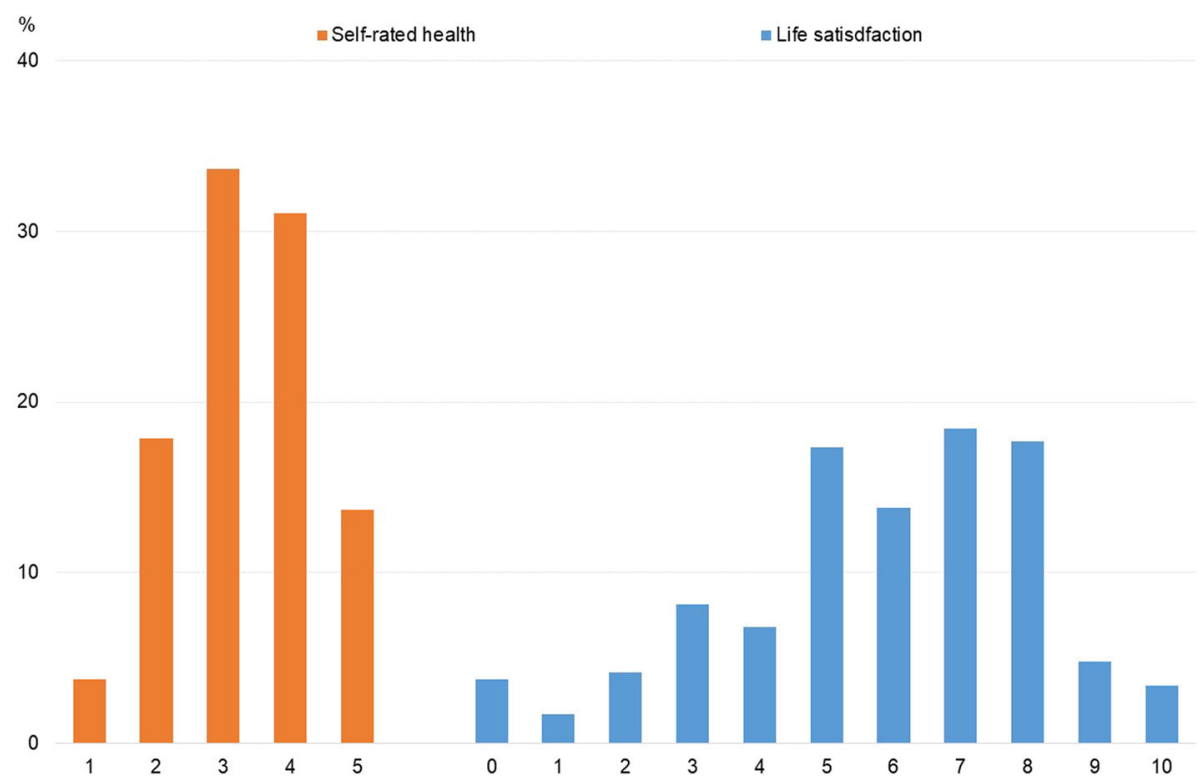

Fig. 1 Distributions of self-rated health and life satisfaction $(N=12,461)$

deprivation indicators. As seen in this table, taxable income was positively associated with both SRH and LS scores, and the percentage of persons with the highest educational attainment was positively associated with SRH scores. Other indicators had no significant or only modest associations with SRH or LS scores. Meanwhile, the seven deprivation indicators had relatively high correlations with each other.

Table 3 shows the results of the principal component analysis. We obtained the first and second principal components, which, when combined, accounted for $78.8 \%$ of the total variance in the data. The first component had highly positive loadings on single-parent households, unemployment, and aged single households, and highly negative loadings on taxable income and highest educational attainment. The second component had highly positive loadings on diminished floor space, unemployment, and aged single households, and a negative loading on house ownership. Judging from the proportion of the variance accounted for by a set of selected seven indicators and the directions of loadings on them, we can roughly argue for the validity of their choice as indicators of municipality-level deprivation. We subsequently constructed three deprivation indices, corresponding to the first and second principal components and their combinations. As mentioned above, we categorized these indices into tertiles.

Table 4 presents the estimation results of multilevel linear regression models to explain SRH scores by municipality-level deprivation derived by the $z$-scoring method and individual-level variables. The SRH score was standardized by its sample $\mathrm{M}$ and SD. The table

Table 2 Pairwise correlation coefficients across municipality-level self-rated health, life satisfaction, and deprivations ( $N=366)$

\begin{tabular}{|c|c|c|c|c|c|c|c|c|c|c|}
\hline & 1 & 2 & 3 & 4 & 5 & 6 & 7 & 8 & M & $S D$ \\
\hline 1. Self-rated health ${ }^{a}$ & & & & & & & & & 3.32 & $(0.25)$ \\
\hline 2. Life satisfaction ${ }^{b}$ & $0.43^{* * * *}$ & & & & & & & & 5.79 & $(0.53)$ \\
\hline 3. Taxable income per capita & $0.13^{+}$ & $0.15^{* *}$ & & & & & & & 1.44 & $(0.44)$ \\
\hline 4. Unemployment rate & $-0.09^{\dagger}$ & $0.10^{\dagger}$ & $-0.35^{* * *}$ & & & & & & 6.4 & \\
\hline 5. \% of persons who graduated from college or above & $0.10^{+}$ & $0.22^{* * *}$ & $0.72^{* * *}$ & $-0.26^{* * *}$ & & & & & 16.6 & \\
\hline 6. \% of aged single households & -0.02 & 0.06 & $-0.56^{* * *}$ & $0.56^{* * *}$ & $-0.54^{* * *}$ & & & & 10.7 & \\
\hline 7. \% of single-parent households & $-0.10^{+}$ & 0.08 & $-0.23^{* * *}$ & $0.25^{* * *}$ & $-0.26^{* * *}$ & $0.19^{* * *}$ & & & 1.7 & \\
\hline 8. \% of owned houses & $-0.11^{*}$ & $-0.10^{\dagger}$ & $-0.48^{* * *}$ & $-0.15^{* *}$ & $-0.44^{* * *}$ & 0.05 & 0.06 & & 65.4 & \\
\hline 9. \% of houses below minimum floor space & 0.07 & 0.06 & $0.48^{* * *}$ & 0.07 & $0.45^{* * *}$ & $-0.24^{* * *}$ & -0.06 & $-0.87^{* * *}$ & 5.4 & \\
\hline
\end{tabular}

a Range: 1-5 (the higher, the better)

b Range: $0-10$ (the higher, the more satisfied)

${ }^{* * *} p<0.001,{ }^{* *} p<0.01,{ }^{*} p<0.05^{\prime}{ }^{\dagger} p<0.1$ 
Table 3 Results of principal component analysis on municipality-level deprivation

\begin{tabular}{lll}
\hline Indicator & First component & Second component \\
\hline Taxable income per capita & -0.51 & 0.13 \\
\% of unemployed persons & 0.38 & 0.36 \\
\% of persons who graduated from college or above & -0.49 & 0.09 \\
\% of aged single households & 0.30 & 0.32 \\
\% of single-parent households & 0.49 & -0.07 \\
\% of owned houses & 0.03 & -0.60 \\
\% of houses below minimum floor space & -0.12 & 0.61 \\
\hline
\end{tabular}

compares the estimation results across Model 1 (which included individual-level deprivation only), Model 2 (which included municipality-level deprivation only), and Model 3 (which included both). As seen in the table, the estimated coefficients on deprivation variables at both levels were largely the same across three models, suggesting that deprivation variables at two levels were associated with SRH largely independently from each other. We confirmed similar results for other indices of municipality-level deprivation and also for LS (not reported but available upon request). These results suggest that it may be largely reasonable to treat individual-level deprivation variables as control variables and focus on the extent of which health behavior and interactions with others mediated the impact of municipality-level deprivation on SRH and LS. Equally important, Table 3 confirms that moderate and high municipality-level deprivation worsened SRH scores by 0.05 SD (standard error [SE]: $0.02 \mathrm{SD}$ ), compared to low deprivation. The table also shows that the magnitude of the association between individual-level deprivation (in terms of income, education, and employment status) and SRH was in the range of 0.21-0.27 SD, much higher than that for municipality-level deprivation.

Table 5 compares the estimated impact of municipalitylevel deprivation on SRH and LS across eight model specifications. The most noticeable finding is that high municipality-level deprivation worsened SRH and LS scores by $0.05-0.06 \mathrm{SD}$ in all model specifications except for the PCA method using the second component (bottom). The results for moderate deprivation were somewhat more mixed; its impact was even larger than high deprivation for LS in some cases while it did not have a significant impact on others. We also found that the

Table 4 Estimation results of a multilevel regression model to explain self-rated health Dependent variable: self-rated health (standardized) $^{a}$

\begin{tabular}{|c|c|c|c|c|c|c|}
\hline & \multicolumn{2}{|l|}{ Model 1} & \multicolumn{2}{|l|}{ Model 2} & \multicolumn{2}{|l|}{ Model 3} \\
\hline & Coef. & SE & Coef. & SE & Coef. & SE \\
\hline \multicolumn{7}{|l|}{ Municipality-level deprivation } \\
\hline Moderate & & & $-0.06^{*}$ & $(0.02)$ & $-0.05^{*}$ & $(0.02)$ \\
\hline High & & & $-0.05^{*}$ & $(0.02)$ & $-0.05^{*}$ & $(0.02)$ \\
\hline \multicolumn{7}{|l|}{ Individual-level } \\
\hline Income poverty & $0.21^{* * *}$ & $(0.03)$ & & & $-0.21^{* * *}$ & $(0.03)$ \\
\hline Lowest educational attainment & $-0.22^{* * *}$ & $(0.05)$ & & & $-0.22^{* * *}$ & $(0.05)$ \\
\hline Unemployed & $-0.27^{* * *}$ & $(0.05)$ & & & $-0.27^{* * *}$ & $(0.05)$ \\
\hline Having no spouse & $-0.15^{* * *}$ & $(0.02)$ & $-0.17^{* * *}$ & $(0.02)$ & $-0.15^{* * *}$ & $(0.02)$ \\
\hline Female & 0.02 & $(0.02)$ & 0.01 & $(0.02)$ & 0.02 & $(0.02)$ \\
\hline Age: $30-39$ years & $-0.19^{* * *}$ & $(0.03)$ & $-0.17^{* * *}$ & $(0.03)$ & $-0.19^{* * *}$ & $(0.03)$ \\
\hline Age: $40-69$ years & $-0.40^{* * *}$ & $(0.03)$ & $-0.39^{* * *}$ & $(0.03)$ & $-0.40^{* * *}$ & $(0.03)$ \\
\hline Age: $50-59$ years & $-0.53^{* * *}$ & $(0.03)$ & $-0.52^{* * *}$ & $(0.03)$ & $-0.53^{* * *}$ & $(0.03)$ \\
\hline Age: 60 or above & $-0.41^{* * *}$ & $(0.03)$ & $-0.39^{* * *}$ & $(0.03)$ & $-0.41^{* * *}$ & $(0.03)$ \\
\hline Surveyed in 2020 & 0.01 & $(0.02)$ & 0.01 & $(0.02)$ & 0.01 & $(0.02)$ \\
\hline
\end{tabular}

$N=12,461$ (in 366 municipalities)

a The higher, the poorer

${ }^{* * *} p<0.001,{ }^{*} p<0.05$ 
Table 5 Estimated association of municipality-level deprivation with self-rated satisfaction and life satisfaction: multilevel regression models ${ }^{a}$

\begin{tabular}{|c|c|c|c|c|}
\hline \multirow{2}{*}{$\begin{array}{l}\text { Dependent variable } \\
\text { Municipality-level deprivation }\end{array}$} & \multicolumn{2}{|c|}{ Self-rated heath $^{\mathbf{b}}$} & \multicolumn{2}{|c|}{ Life satisfaction $^{c}$} \\
\hline & Coef. & $S E$ & Coef. & $S E$ \\
\hline \multicolumn{5}{|l|}{$z$-scoring method } \\
\hline Moderate & $-0.05^{*}$ & $(0.02)$ & $-0.06^{* *}$ & $(0.02)$ \\
\hline High & $-0.05^{*}$ & $(0.02)$ & $-0.05^{*}$ & $(0.02)$ \\
\hline \multicolumn{5}{|l|}{ PCA ${ }^{d}$ method } \\
\hline \multicolumn{5}{|l|}{ First and second components } \\
\hline Moderate & -0.04 & $(0.02)$ & $-0.09^{* * *}$ & $(0.02)$ \\
\hline High & $-0.05^{*}$ & $(0.02)$ & $-0.06^{* *}$ & $(0.02)$ \\
\hline \multicolumn{5}{|l|}{ First component } \\
\hline Moderate & -0.01 & $(0.02)$ & -0.00 & $(0.02)$ \\
\hline High & $-0.06^{* *}$ & $(0.02)$ & $-0.05^{*}$ & $(0.02)$ \\
\hline \multicolumn{5}{|l|}{ Second component } \\
\hline Moderate & 0.01 & $(0.03)$ & -0.03 & $(0.03)$ \\
\hline High & 0.01 & $(0.02)$ & -0.02 & $(0.03)$ \\
\hline $\begin{array}{l}N=12,461 \text { (in } 366 \text { municipalities) } \\
\text { a Controlled for individual-level depr } \\
\text { b The higher, the better. Standardize } \\
{ }^{\mathrm{C}} \text { The higher, the more satisfied. Star } \\
{ }^{* * *} p<0.001,{ }^{* *} p<0.01,{ }^{*} p<0.05\end{array}$ & 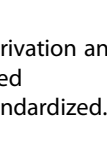 & (2) & 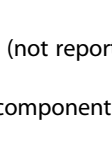 & \\
\hline
\end{tabular}

second principal component had no association with SRH or LS.

Table 6 summarizes the mediation analysis for SRH using the $z$-scoring method. We found that health behavior was negatively associated with high municipalitylevel deprivation (top panel), while interactions with others had no significant relationship with deprivation (second). We also found that both health behavior and interactions with others were negatively associated with poor SRH (third). Hence, we can assume that there may be only one mediation process: health behavior mediated the impact of high deprivation. Indeed, Table 6 shows that health behavior mediated $21.1 \%$ (SE: 9.5\%) of the association between high deprivation and SRH, while there was no other significant mediation effect.

We obtained similar results for other combinations of the outcome (SRH or LS) and methods ( $z$-scoring and PCA [using the combined components or the first component]), although we have not presented them to conserve space. In all cases, we found that (1) health behavior was negatively associated with high deprivation, (2) interactions with others were not associated with deprivation, and (3) both health behavior and interactions with others were negatively associated with outcome scores, as seen in Table 6.

These results allowed us to concentrate on the mediating effect of health behavior on the impact of high deprivation. Table 7 compares these effects across six combinations of outcomes (SRH and LS) and methods
Table 6 Mediating effects of health behavior and interactions with others on the impact of municipality-level deprivation (derived by the $z$-scoring method) on self-rated health ${ }^{a}$

\begin{tabular}{|c|c|c|c|}
\hline & & Coef. & SE \\
\hline \multicolumn{4}{|l|}{ Health behavior ${ }^{b}$} \\
\hline Moderate deprivation & $\beta_{11}$ & -0.04 & $(0.02)$ \\
\hline High deprivation & $\beta_{12}$ & $-0.05^{*}$ & $(0.02)$ \\
\hline \multicolumn{4}{|l|}{ Interactions with others ${ }^{\mathrm{b}}$} \\
\hline Moderate deprivation & $\beta_{21}$ & -0.03 & $(0.02)$ \\
\hline High deprivation & $\beta_{22}$ & -0.03 & $(0.02)$ \\
\hline \multicolumn{4}{|l|}{ Self-rated health ${ }^{b, c}$} \\
\hline Moderate deprivation & $\beta_{31}$ & $-0.04^{*}$ & $(0.02)$ \\
\hline High deprivation & $\beta_{32}$ & -0.04 & $(0.02)$ \\
\hline Health behavior & $\gamma_{1}$ & $0.21^{* * *}$ & $(0.01)$ \\
\hline Interactions with others & $\gamma_{2}$ & $0.09^{* * *}$ & $(0.01)$ \\
\hline \multicolumn{4}{|c|}{ Mediating effect on the impact of high deprivation on self-rated health } \\
\hline Health behavior & $\beta_{12} \gamma_{1}$ & $-0.011^{*}$ & $(0.005)$ \\
\hline \multicolumn{2}{|c|}{$\%$ proportion: $\beta_{12} \gamma_{1} /\left(\beta_{32}+\beta_{12} \gamma_{1}+\beta_{22} \gamma_{2}\right) \times 100$} & $21.1^{*}$ & $(9.5)$ \\
\hline 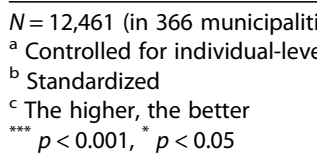 & es (not repor & & \\
\hline
\end{tabular}

( $z$-scoring and PCA methods [using the combined components or the first component]). Table 7 shows that in all cases, the impact of high deprivation was mediated by health behavior, as already seen in the case of the combination of SRH and the $z$-scoring method. The proportional impact of high deprivation on SRH by health behavior ranged from 20.3\% (SE: 10.1\%) to 25.2\% (SE: $10.0 \%)$. For LS, the proportion was in a somewhat wider range, from $17.6 \%$ (SE: $8.7 \%$ ) to $33.1 \%$ (SE: 13.8\%).

Table 8 summarizes the estimation results for each of seven types of health behavior. We estimated the structural equation model separately for each behavior by replacing the variable of overall health variable by a binary variable of that behavior. For each health behavior, the table presents (1) the association with SRH and LS, (2) the association with high municipality-level deprivation (derived by the $z$-scoring method), and (3) the mediating effect of high deprivation on SRH and LH. While all seven types of health behavior were associated with SRH and LS, eating a balanced diet and getting enough sleep were most closely related to both of them. Meanwhile, the mediating effect of high deprivation was observed only for exercising and getting enough sleep.

\section{Discussion}

The current study showed that municipality-level deprivation depressed and individual's general health conditions, which were measured by SRH as well as SWB, which was represented by LS. The results did not 
Table 7 Mediating effect of health behavior on the impact of high deprivation at the municipality level ${ }^{a}$

\begin{tabular}{|c|c|c|c|c|c|}
\hline & & Self-rate & & Life satis & \\
\hline & & & (SE) & & (SE) \\
\hline$z$-scoring method & Effect & $-0.011^{*}$ & $(0.005)$ & $-0.01^{*}$ & $(0.006)$ \\
\hline & $\%$ proportion & $21.1^{*}$ & $(9.5)$ & $24.8^{*}$ & $(12.5)$ \\
\hline PCA ${ }^{e}$ method & & & & & \\
\hline First and second components & Effect & $-0.01^{*}$ & $(0.00)$ & $-0.01^{*}$ & $(0.01)$ \\
\hline & $\%$ proportion & $20.3^{*}$ & $(10.1)$ & $17.6^{*}$ & $(8.7)$ \\
\hline First component & Effect & $-0.02^{*}$ & $(0.01)$ & $-0.02^{* * *}$ & $(0.01)$ \\
\hline & $\%$ proportion & $25.2^{*}$ & $(10.0)$ & $33.1^{*}$ & $(13.8)$ \\
\hline
\end{tabular}

$N=12,461$ (in 366 municipalities)

${ }^{a}$ Controlled for individual-level covariates (not reported)

${ }^{\mathrm{b}}$ Standardized

c The higher, the better

d The higher, the more satisfied

e Principal component analysis

${ }^{* * *} p<0.001,{ }^{*} p<0.05$

Table 8 Estimation results for each health behavior ${ }^{a}$

Self-rated health ${ }^{\mathrm{b}, c}$

Exercising

Getting enough sleep

Refraining from smoking

Refraining from excess alcohol consumption

Avoiding the accumulation of stress

Going for regular checkups

Association with high deprivation ${ }^{\mathrm{e}}\left(\beta_{12}\right)$

Eating a balanced diet

Exercising

Getting enough sleep

Refraining from smoking

Refraining from excess alcohol consumption

Avoiding the accumulation of stress

Going for regular checkups

Moderating effect on the impact of high deprivation $\left(\beta_{12} \gamma_{1}\right)$

Eating a balanced diet

Exercising

Getting enough sleep

Refraining from smoking

Refraining from excess alcohol consumption

Avoiding the accumulation of stress

Going for regular checkups
$0.40^{* * *}$

$0.36^{* * *}$

$0.32^{* * *}$

$0.13^{* * *}$

$0.11^{* * *}$

(0.02)

(0.02)

(0.02)

$0.27^{* * *}$

$0.08^{* * *}$

(0.02)

(0.02)

$-0.02$

$-0.03^{* *}$

$-0.03^{* *}$

$-0.00$

0.00

$-0.01$

$-0.01$

$-0.008$

$-0.011^{* *}$

$-0.009^{* *}$

(0.01)

(0.01)

$(0.01)$

(0.01)

(0.01)

$(0.01)$

(0.01)

(0.005)

$(0.004)$

(0.004)

0.000

0.000

$-0.003$

$(0.001)$

(0.001)

$(0.003)$

$-0.001$

$(0.001)$
Life satisfaction ${ }^{\mathrm{b}, \mathrm{d}}$

(SE)

(SE)

(0.02)

(0.02)

(0.02)

$0.26^{* * *}$

$-0.02$

$(0.01)$

$-0.03^{* *}$

$-0.03^{* *}$

$-0.01$

(0.004)

$-0.007$

$-0.008^{* *}$

$-0.010^{* *}$

0.000

(0.002)

0.001

$(0.004)$

$-0.004$

a Controlled for individual-level covariates (not reported)

b Standardized

c The higher, the better

${ }^{d}$ The higher, the more satisfied

${ }^{\mathrm{e}}$ Derived by the $z$-scoring method

${ }^{* * *} p<0.001,{ }^{* *} p<0.01$ 
differ significantly between the $z$-scoring and PCA methods. These findings were consistent with those obtained in previous studies and provided evidence of the contextual, adverse impact of area-level deprivation on health outcomes [4-17].

We obtained two additional observations. First, the impact of municipality-level deprivation was generally modest. Specifically, living in municipalities with moderate or high deprivation worsened SRH or LS scores by a $0.05-0.09 \mathrm{SD}$, compared to those living in municipalities with low deprivation, as observed in Table 5. The magnitude of this impact was one fifth to one fourth of that of the association of SRH with individual-level deprivation in terms of income (0.21SD), education (0.22SD), or employment status (0.27SD), as observed in Table 4. These results indicated that the impact of arealevel deprivation on SRH or LS was in general much limited compared to individual-level deprivation.

Second, health behavior mediated the impact of high deprivation at the municipality level on SRH and LS. Interactions with others, which had a favorable association with SRH and LS, albeit to a lesser extent than health behavior, were not much affected by municipality-level deprivation. By comparison, area-level deprivation was found to discourage individuals from exhibiting healthy behavior. One possible explanation is that individuals living in highly deprived municipalities may have more chances to observe and be influenced by the unhealthy behavior of neighbors with low socioeconomic status.

Regarding the mediating effect of health behavior, three factors should be noted. First, the mediating effect worked only if area-level deprivation was high. This result suggests that area-level deprivation must be sufficiently high to make neighbors' unhealthy behavior so commonly observed to affect an individual's behavior. Second, the proportional impact of deprivation on SRH and LS mediated by health behavior ranged from 17.6 to $33.1 \%$, meaning that health behavior is not a dominant, albeit non-negligible, mediator of the impact of arealevel deprivation. Third, the results suggest that exercising and getting enough sleep exhibit greater mediating effects than other types of health behavior.

However, we cannot rule out the possibility that there may be important mediators other than health behavior and interactions with others. Indeed, studies have shown that perceptions of neighborhood and built environment mediated the impact of area-level deprivation on health outcomes [46, 47]. Even so, the results of the current study point to the possibility that policy measures to promote a healthy lifestyle can help to alleviate the adverse impact of area-level deprivation.

The current study has several limitations. First, the results may depend on the choice of measures of municipality-level deprivation. The selection of municipality-level indicators in this study was generally in line with preceding studies [4, 21-23] and we believe that they are able to capture a comprehensive picture of the socioeconomic positions of each municipality. However, we cannot rule out arbitrariness in the choice of indicators, and single indices of area-level deprivation cannot be free from criticism. We compared the results between $z$-scoring and PCA methods to examine the robustness of the estimated results. However, equal weighting in the $z$-scoring method requires more justification rather than simplicity or replicability, whereas the weights assigned to the indicators in the PCA method have no clear theoretical basis. In this regard, Nakaya et al.'s approach $[6,11,48$ 50], which provides a foundation to the choice and weighting of area-level indicators by linking them to the individuallevel poverty, must be a promising direction to develop better area-level deprivation indices.

Second, we should be cautious in interpreting the results of our mediation analysis. The implicitly assumed causations from municipality-level deprivation to health behavior and from health behavior to SRH and LS had no rigorous theoretical ground, and the temporal precedence of municipality-level deprivation over other variables was not guaranteed. Moreover, the observed mediating mechanism may have been confounded by a third variable.

Third, the study sample was not fully representative of the entire population in Japan, especially in terms of underweighted residents in the metropolitan areas. The observed results were not adjusted by weighted estimates taking into account the actual demographic distribution, probably causing estimation biases.

In addition to these key limitations, we recognize that cross-sectional analysis in the study cannot precisely identify causation from area-level deprivation to individual-level health and well-being. We also ignored the determinants of individuals' choice of where to live and a possible time lag between deprivation and health outcomes. To address these issues, we would need a longitudinal dataset.

\section{Conclusions}

This study showed that area-level deprivation modestly depresses an individual's general health conditions and SWB, independent of individual-level deprivation. We also observed that health behavior mediated the impact of area-level deprivation. The results underscore the need for public health policies to improve area-level socioeconomic conditions and to promote healthy lifestyles to alleviate the negative impact of area-level deprivation.

\section{Abbreviations}

CAO: Cabinet office; LS: Life satisfaction; MHLW: Ministry of Health, Labour and Welfare; M: Mean; PCA: Principal component analysis; SD: Standard deviation; SE: Standard error; SRH: Self-rated health; SWB: Subjective wellbeing 


\section{Acknowledgements}

This study was conducted as a part of the Project "Research on Well-Being and Quality of Life" undertaken at the Cabinet Office of the Japanese Government.

\section{Authors' contributions}

TOm and TN organized this research project and conceptualized and designed this study. KH conducted data collection and TOs performed the analysis. TOs prepared the initial manuscript and $\mathrm{KH}, \mathrm{TN}$, and TOm significantly contributed to revising it. All authors have read and approved the final manuscript.

\section{Funding}

This study was financially supported by a grant from the Japan Society for the Promotion of Science (JSPS) (Grant Number: 20 K01722). The funding body had no role in the design of the study, in the collection, analysis, and interpretation of the data, or in writing the manuscript.

\section{Availability of data and materials}

The data that support the findings of this study are available from the CAO but restrictions apply to the availability of this data, which were used under admission for the current study, and so are not publicly available. Data are, however, available from the authors upon reasonable request and with permission from the CAO.

\section{Declarations}

\section{Ethics approval and consent to participate}

This study used data obtained from a nationwide population-based nationwide internet survey conducted in the research project of the Cabinet Office (CAO) of the Japanese government in October 2019 and again in February 2020. The survey was conducted in accordance with the Statistics Law in Japan, which governs the statistical, legal, ethical, and other rules for surveys conducted by the government. Informed consent was obtained from all participants. We obtained the data of the survey with the permission of the $\mathrm{CAO}$; therefore, ethics approval was not required for the current study.

\section{Consent for publication}

Not applicable.

\section{Competing interests}

The authors declare no competing interests.

\section{Author details}

${ }^{1}$ Institute of Economic Research, Hitotsubashi University, 2-1 Naka, Kunitachi, Tokyo 186-8603, Japan. 'Survey Research Center, 3-13-5 Nihonbashi, Chuo-ku, Tokyo 103-0027, Japan. ${ }^{3}$ Japan Cabinet Office, 1-6-1 Nagatacho, Chiyoda-ku, Tokyo 100-8914, Japan. ${ }^{4}$ Osaka University, 1-7 Machikaneyama Toyonaka, Osaka 560-0043, Japan.

Received: 20 July 2020 Accepted: 7 March 2021

Published online: 17 March 2021

\section{References}

1. Arcaya MC, Tucker-Seeley RD, Kim R, Schnake-Mahl A, So M, Subramanian SV. Research on neighborhood effects on health in the United States: a systematic review of study characteristics. Soc Sci Med. 2016;168:16-29. https://doi.org/10.1016/j.socscimed.2016.08.047.

2. Diez Roux AV, Mair C. Neighborhoods and health. Ann N Y Acad Sci. 2010; 1186(1):125-45. https://doi.org/10.1111/j.1749-6632.2009.05333.x.

3. Pickett KE, Pearl M. Multilevel analyses of neighbourhood socioeconomic context and health outcomes: a critical review. J Epidemiol Community Health. 2001;55(2):111-22. https://doi.org/10.1136/jech.55.2.111.

4. Fukuda Y, Nakamura K, Takano T. Higher mortality in areas of lower socioeconomic position measured by a single index of deprivation in Japan. Public Health. 2007;121(3):163-73. https://doi.org/10.1016/j.puhe.2006.10.015.

5. Meijer M, Röhl J, Bloomfield K, Grittner U. Do neighborhoods affect individual mortality? A systematic review and meta-analysis of multilevel studies. Soc Sci Med. 2012;74(8):1204-12. https://doi.org/10.1016/j. socscimed.2011.11.034.
6. Nakaya T, Honjo K, Hanibuchi T, Ikeda A, Iso H, Inoue M, Sawada N, Tsugane S, the Japan Public Health Center-based Prospective Study Group. Associations of all-cause mortality with census-based neighbourhood deprivation and population density in Japan: a multilevel survival analysis. PLoS One. 2014;9(6):e97802. https://doi.org/10.1371/journal.pone.0097802.

7. Turrell G, Kavanagh A, Draper G, Subramanian SV. Do places affect the probability of death in Australia? A multilevel study of area-level disadvantage, individual-level socioeconomic position and all-cause mortality, 1998-2000. J Epidemiol Community Health. 2007;61(1):13-9. https://doi.org/10.1136/jech.2006.046094.

8. Dalstra JA, Kunst AE, Borrell C, Breeze E, Cambois E, Costa G, Geurts JJM Lahelma E, van Oyen H, Rasmussen NK, Regidor E, Spadea T, Mackenbach JP. Socioeconomic differences in the prevalence of common chronic diseases: an overview of eight European countries. Int J Epidemiol. 2005; 34(2):316-26. https://doi.org/10.1093/ije/dyh386.

9. Janevic T, Stein CR, Savitz DA, Kaufman JS, Mason SM, Herring AH. Neighborhood deprivation and adverse birth outcomes among diverse ethnic groups. Ann Epidemiol. 2010;20(6):445-51. https://doi.org/10.1016/j.a nnepidem.2010.02.010

10. Lòpez-De Fede A, Stewart JE, Hardin JW, Mayfield-Smith K. Comparison of small-area deprivation measures as predictors of chronic disease burden in a low-income population. Int J Equity Health. 2016;15(1):89. https://doi.org/1 0.1186/s12939-016-0378-9

11. Miki Y, Inoue M, Ikeda A, Sawada N, Nakaya T, Shimazu T, Iwasaki M, Yamaji T, Sasazuki S, Shibuya K, Tsugane S, for the JPHC Study Group. Neighborhood deprivation and risk of cancer incidence, mortality and survival: results from a population-based cohort study in Japan. PLoS One. 2014;9(9):e106729. https://doi.org/10.1371/journal.pone.0106729.

12. Remes $\mathrm{O}$, Lafortune L, Wainwright $N$, Surtees $P$, Khaw KT, Brayne $C$. Association between area deprivation and major depressive disorder in British men and women: a cohort study. BMJ Open. 2019;9(11):e027530. https://doi.org/10.1136/bmjopen-2018-027530.

13. Remes $O$, Wainwright $N$, Surtees $P$, Lafortune $L$, Khaw KT, Brayne C. Sex differences in the association between area deprivation and generalised anxiety disorder: British population study. BMJ Open. 2017;7(5):e013590. https://doi.org/10.1136/bmjopen-2016-013590.

14. Ma XG, Fleischer NL, Liu JH, Hardin JW, Zhao G, Liese AD. Neighborhood deprivation and preterm birth: an application of propensity score matching. Ann Epidemiol. 2015;25(2):120-5 https://doi.org/10.1016/j.annepidem.2 014.11.021.

15. Mehra R, Shebl FM, Cunningham SD, Magriples U, Barrette E, Herrera C, Kozhimannil KB, Ickovics JR. Area-level deprivation and preterm birth: results from a national, commercially-insured population. BMC Public Health. 2019; 19(1):236. https://doi.org/10.1186/s12889-019-6533-7.

16. Algren $\mathrm{MH}$, Bak CK, Berg-Beckhoff G, Andersen PT. Health-risk behaviour in deprived neighbourhoods compared with non-deprived neighbourhoods: a systematic literature review of quantitative observational studies. PLoS One. 2015;10(10):e0139297. https://doi.org/10.1371/journal.pone.0139297.

17. Vinther-Larsen M, Huckle T, You R, Casswell S. Area level deprivation and drinking patterns among adolescents. Health Place. 2013;19:53-8. https://dx. doi.org/j.healthplace.2012.09.014. https://doi.org/10.1016/j.healthplace.2012. 09.014 .

18. Allik M, Leyland A, Travassos Ichihara MY, Dundas R. Creating small-area deprivation indices: a guide for stages and options. J Epidemiol Community Health. 2020;74(1):20-5. https://doi.org/10.1136/jech-2019-213255.

19. Noble M, Wright $G$, Smith G, Dibben C. Measuring multiple deprivation at the small-area level. Environ Plan A. 2006;38(1):169-85. https://doi.org/10.1 068/a37168

20. Townsend P, Phillimore $P$, Beattie $A$. Health and deprivation: inequality and the north. London: Croom Helm; 1988.

21. Carstairs V, Morris R. Deprivation and health in Scotland. Aberdeen: Aberdeen University Press; 1991.

22. Jarman B. Identification of underprivileged areas. Br Med J. 1983;286(6379): 1705-9. https://doi.org/10.1136/bmj.286.6379.1705.

23. Decancq K, Lugo MA. Weights in multidimensional indices of wellbeing: an overview. Econom Rev. 2013;32(1):7-34. https://doi.org/10.1080/07474938.2 012.690641

24. Lalloué B, Monnez J-M, Padilla C, Wahida Kihal W, Le Meur N, Zmirou-Navier D, et al. A statistical procedure to create a neighborhood socioeconomic index for health inequalities analysis. Int J Equity Health. 2013;12(1):21. https://doi.org/10.1186/1475-9276-12-21. 
25. Messer LC, Laraia BA, Kaufman JS, Eyster J, Holzman C, Culhane J, Elo I, Burke JG, O'Campo P. The development of a standardized neighborhood deprivation index. J Urban Health. 2006;83(6):1041-62. https://doi.org/10.1 007/s11524-006-9094-x.

26. Idler EL, Benyamini Y. Self-rated health and mortality: a review of twentyseven community studies. J Health Soc Behav. 1997;38(1):21-37. https://doi. org/10.2307/2955359.

27. Jylhä M. What is self-rated health and why does it predict mortality? Towards a unified conceptual model. Soc Sci Med. 2009;69(3):307-16. https://doi.org/10.1016/j.socscimed.2009.05.013.

28. Ballas D, Tranmer M. Happy people or happy places? A multilevel modeling approach to the analysis of happiness and well-being. Int Regional Sci Rev. 2012;35(1):70-102. https://doi.org/10.1177/0160017611403737.

29. Oswald AJ, Wu S. Objective confirmation of subjective measures of human well-being: evidence from the U.S.A. Science. 2010;327(5965):576-9. https:// doi.org/10.1126/science.1180606.

30. Rentfrow PJ, Mellander C, Florida R. Happy states of America: a state-level analysis of psychological, economic, and social well-being. J Res Personal. 2009;43(6):1073-82. https://doi.org/10.1016/j.jrp.2009.08.005.

31. Shields MA, Price SW, Wooden M. Life satisfaction and the economic and social characteristics of neighbourhoods. J Popul Econ. 2009;22(2):421-43. https://doi.org/10.1007/s00148-007-0146-7.

32. Hildebrand V, Van Kerm P. Income inequality and self-rated health status: evidence from the European Community household panel. Demography. 2009:46(4):805-25. https://doi.org/10.1353/dem.0.0071.

33. Ngamaba KH, Panagioti M, Armitage CJ. Income inequality and subjective well-being: a systematic review and meta-analysis. Qual Life Res. 2018;27(3): 577-96. https://doi.org/10.1007/s11136-017-1719-x.

34. Subramanian SV, Kawachi I. Income inequality and health: what have we learned so far? Epidemiol Rev. 2004;26(1):78-91. https://doi.org/10.1093/ epirev/mxh003.

35. Pollack CE, Cubbin C, Ahn D, Winkleby M. Neighbourhood deprivation and alcohol consumption: does the availability of alcohol play a role? Int J Epidemiol. 2005;34(4):772-80. https://doi.org/10.1093/ije/dyi026.

36. Chaparro MP, Benzeval M, Richardson E, Mitchell R. Neighborhood deprivation and biomarkers of health in Britain: the mediating role of the physical environment. BMC Public Health. 2018;18(1):801. https://doi.org/1 0.1186/s12889-018-5667-3.

37. Giordano GN, Lindstrom M. The impact of changes in different aspects of social capital and material conditions on self-rated health over time: a longitudinal cohort study. Soc Sci Med. 2010;70(5):700-10. https://doi.org/1 0.1016/j.socscimed.2009.10.044.

38. Sargent-Cox K, Cherbuin N, Morris L, Butterworth P, Anstey KJ. The effect of health behavior change on self-rated health across the adult life course: a longitudinal cohort study. Prev Med. 2014;58:75-80. https://doi.org/10.1016/ j.ypmed.2013.10.017.

39. Strine TW, Chapman DP, Balluz LS, Moriarty DG, Mokdad AH. The associations between life satisfaction and health-related quality of life, chronic illness, and health behaviors among U.S. community-dwelling adults. J Community Health. 2008;33(1):40-50. https://doi.org/10.1007/s1 0900-007-9066-4.

40. Van der Horst M, Coffé $\mathrm{H}$. How friendship network characteristics influence subjective well-being. Soc Indic Res. 2012;107(3):509-29. https://doi.org/10.1 007/s11205-011-9861-2.

41. Fukuda $Y$, Nakao H, Yahata $Y$, Imai H. Are health inequalities increasing in Japan? The trends of 1955 to 2000. Biosci Trends. 2007;1(1):38-42.

42. Nomura S, Sakamoto H, Glenn S, Tsugawa Y, Abe SK, Rahmen MD, et al. Population health and regional variations of disease burden in Japan, 19902015: a systematic subnational analysis for the global burden of disease study. Lancet. 2017;390(10101):1521-38. https://doi.org/10.1016/S0140-673 6(17)31544-1.

43. Ministry of Health, Labor and Welfare. Comprehensive Survey of Living Conditions. 2017. https://s://www.mhlw.go.jp/toukei/saikin/hw/k-tyosa/ktyosa16/. Accessed 15 July 2020.

44. Ministry of Land, Infrastructure, Transport and Tourism. Basic Plan for Housing. 2011. https://://www.mlit.go.jp/jutakukentiku/house/torikumi/ jyuseikatsu/kihonkeikaku.pdf. Accessed 16 July 2020.

45. Ministry of Internal Affairs and Communications. Statistical Observations of Municipalities. 2020. https://s://www.stat.go.jp/data/s-sugata/index.html. Accessed 16 July 2020
46. Poortinga W, Dunstan FD, Fone DL. Neighbourhood deprivation and selfrated health: the role of perceptions of the neighbourhood and of housing problems. Health Place. 2008;14(3):562-75. https://doi.org/10.1016/j.hea Ithplace.2007.10.003.

47. Schüle SA, Bolte G. Interactive and independent associations between the socioeconomic and objective built environment on the neighbourhood level and individual health: a systematic review of multilevel studies. PLoS One. 2015;10(4):e0123456. https://doi.org/10.1371/journal.pone.0123456.

48. Honjo K, Iso H, Nakaya T, Hanibuchi T, Ikeda A, Inoue M, Sawada N, Tsugane $\mathrm{S}$, Japan public health center-based prospective study group. Impact of neighborhood socioeconomic conditions on the risk of stroke in Japan. J Epidemiol. 2015;25(3):254-60. https://doi.org/10.2188/jea.JE20140117.

49. Ito Y, Nakaya T, Nakayama T, Miyashiro I, loka A, Tsukuma H, Rachet B. Socioeconomic inequalities in cancer survival: a population-based study of adult patients diagnosed in Osaka, Japan, during the period 1993-2004. Acta Oncol. 2014;53(10):1423-33. https://doi.org/10.3109/0284186X.2014. 912350.

50. Nakaya T, Ito Y, editors. The atlas of health inequalities in Japan. Switzerland: Springer Nature; 2000.

\section{Publisher's Note}

Springer Nature remains neutral with regard to jurisdictional claims in published maps and institutional affiliations.
Ready to submit your research? Choose BMC and benefit from:

- fast, convenient online submission

- thorough peer review by experienced researchers in your field

- rapid publication on acceptance

- support for research data, including large and complex data types

- gold Open Access which fosters wider collaboration and increased citations

- maximum visibility for your research: over $100 \mathrm{M}$ website views per year

At $\mathrm{BMC}$, research is always in progress.

Learn more biomedcentral.com/submissions 